\title{
Decarburized Simulation Analysis of the Crankshaft of JB36-400 Press
}

\author{
Qing-qing Li \\ Department of Mechanical Engineering \\ Yang Zhou University \\ Yang Zhou, China
}

Yi Pan

Department of Mechanical Engineering Yang Zhou University

Yang Zhou, China

\author{
Rong-fa Chen* \\ Department of Mechanical Engineering \\ Yang Zhou University \\ Yang Zhou, China \\ 15052508818 \\ rfchen@yzu.edu.cn
}

Long Wu

Department of Mechanical Engineering

Yang Zhou University

Yang Zhou, China
Tao Liu

Department of Mechanical Engineering

Yang Zhou University

Yang Zhou, China

Hua Yang

Department of Mechanical Engineering

Yang Zhou University

Yang Zhou, China

\begin{abstract}
The thickness of decarburization layer of crankshaft of JB36-400 press was simulated by the DEFORM-3D software. The results indicated that the minimum decarburization layer was obtained at $830^{\circ} \mathrm{C}$ and holding for $120 \mathrm{~min}$ and the mechanical properties and performance can be met the requirements. The experiment and theoretical simulation were consistent, the main causes of the error were temperature uniformity of furnace and the surface conditions of crankshaft.
\end{abstract}

Keywords-DEFORM-3D; decarburized simulation; heat treatment

\section{INTRODUCTION}

Decarburization is one of the common problems when they were heated during the heating process[1-3]. The strength and wear resistance of carbon steel with decarburization are decreased [4-8]. DEFORM-3D is a finite element simulation software of metal forming, designed for forging, rolling, extrusion, heat treatment and metal forming process, and helps to provide an extremely valuable data during the process analytical[9,10]. The decarburized layer of the crankshaft of JB36-400 press during heat treatment process is simulated by the DEFORM-3D software in this paper, and the results of experiment was consistent with the simulation, the quality of crankshafts was improved a lot.

\section{EXPERIMENTAL PROGRAM AND PROCESS}

The decarburization of crankshaft during heat treatment was simulated by the DEFORM-3D software. The crankshafts were experimented by the heat treatment, and the results of decarburization were measured by the metallographic microscope XJP-200. The analysis was made between the results of experimental and simulation.

\section{RESULTS AND DISCUSSION}

\section{A. Simulation results of crankshaft}

The depths of decarburized layer at temperature of $800^{\circ} \mathrm{C}$ for holding time were respectively $60 \mathrm{~min}, 120 \mathrm{~min}$, $180 \mathrm{~min}$ were shown in Fig.1, and the results of $830^{\circ} \mathrm{C}, 860^{\circ} \mathrm{C}$ were displayed in Fig.2 and Fig.3. The decarburized layer can be seen from axial and radial cross-section of the crankshaft. It was obvious that the depth of decarburization layer gradually increased with the longer time and the higher temperature. The carburization depths of different quenching temperature and holding time were shown in table.1. From the data, one can be seen that decarburization layer is $0.055 \mathrm{~mm}$ at the temperature of $800^{\circ} \mathrm{C}$ and holding time of $60 \mathrm{~min} .0 .185 \mathrm{~mm}$ was correspond to $860^{\circ} \mathrm{C}$ and $180 \mathrm{~min}$. By comparative analysis, the conclusion was that at $830^{\circ} \mathrm{C}$ and holding for $120 \mathrm{~min}$, the crankshaft was fully austenitized and the minimum decarburization layer was obtained. The mechanical properties and performance can be met the requirements.
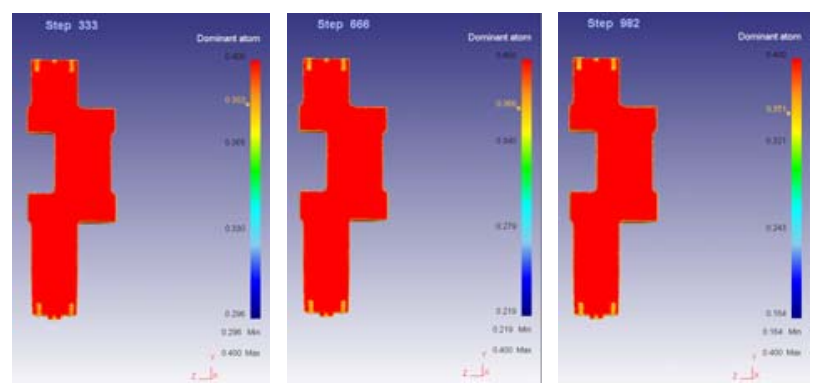


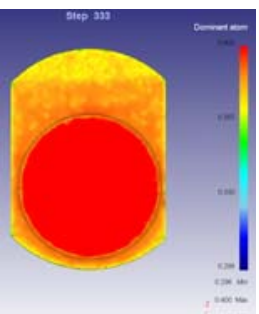

(a) $60 \mathrm{~min}$



(b) $120 \mathrm{~min}$

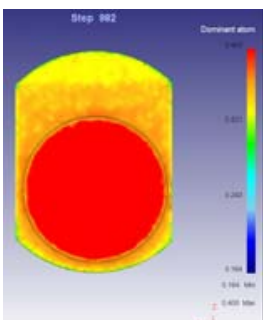

(c)180min
(Cross-section of the crankshaft )

Fig.1 The simulated decarburization of crankshaft at different holding time at $800^{\circ} \mathrm{C}$ (a) $60 \mathrm{~min}$

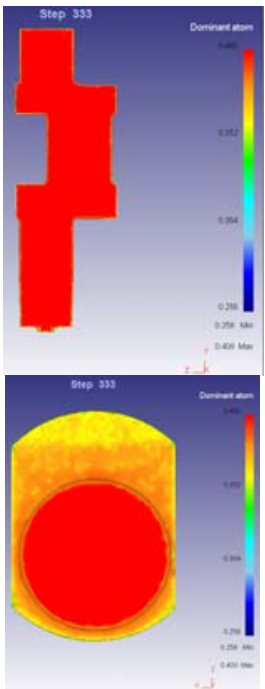

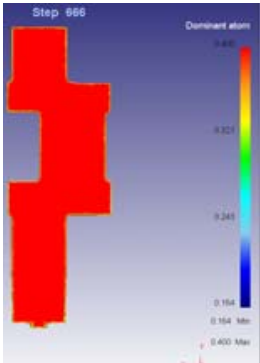

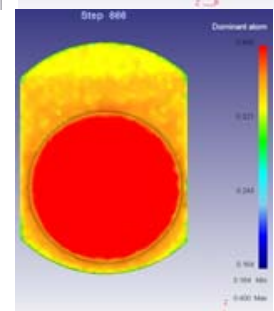

(b) $120 \mathrm{~min}$
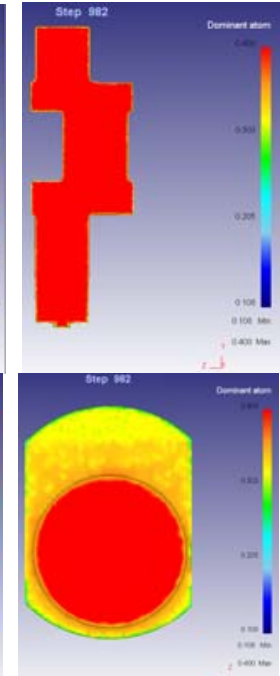

(c) $180 \mathrm{~min}$
Fig.2 The simulated decarburization of crankshaft at different holding time at $830^{\circ} \mathrm{C}$
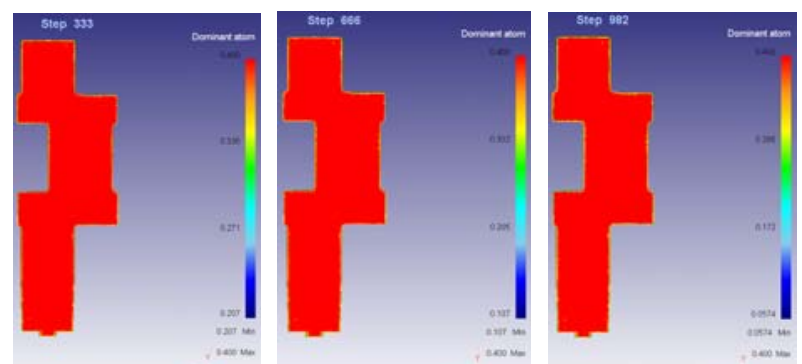

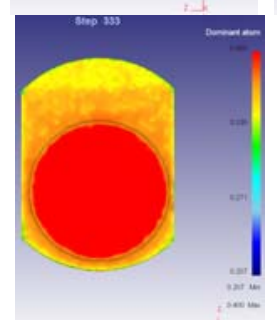

(a) $60 \mathrm{~min}$

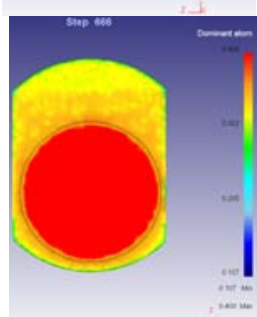

(b) $120 \mathrm{~min}$

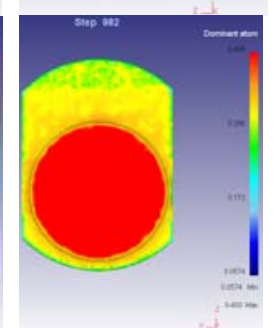

(c) $180 \mathrm{~min}$
Fig.3 The simulated decarburization of crankshaft at different holding time at $860^{\circ} \mathrm{C}$
TABLE I . THE EXPERIMENTAL RESULTS OF THICKNESS OF DECARBURIZED LAYER

\begin{tabular}{|c|c|c|c|}
\hline $\begin{array}{c}\text { Quenching } \\
\text { temperature/ } \\
{ }^{\circ} \mathbf{C}\end{array}$ & $\begin{array}{c}\text { Holding } \\
\text { time/min }\end{array}$ & $\begin{array}{c}\text { Average } \\
\text { decarburized } \\
\text { thickness } \\
\text { /mm }\end{array}$ & $\begin{array}{c}\text { Rectified } \\
\text { values/mm }\end{array}$ \\
\hline \multirow{4}{*}{800} & 60 & 0.52 & 0.052 \\
\cline { 2 - 4 } & 120 & 1.20 & 0.120 \\
\cline { 2 - 4 } & 180 & 1.53 & 0.153 \\
\hline \multirow{3}{*}{830} & 60 & 0.55 & 0.055 \\
\cline { 2 - 4 } & 120 & 1.38 & 0.138 \\
\cline { 2 - 4 } & 180 & 1.70 & 0.170 \\
\cline { 2 - 4 } 860 & 60 & 0.58 & 0.058 \\
\cline { 2 - 4 } & 120 & 1.43 & 0.143 \\
\hline \multirow{3}{*}{} & 180 & 1.85 & 0.185 \\
\hline
\end{tabular}

\section{B. The analysis of experimental results}

The samples of the crankshaft were heated to $830^{\circ} \mathrm{C}$, with holding respectively 60min, $120 \mathrm{~min}, 180 \mathrm{~min}$, and quenched in oil. The thicknesses of the decarburized layer were shown in Fig. 4.

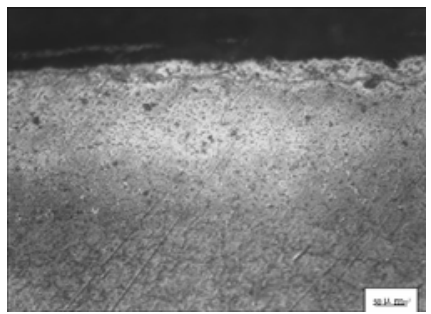

(a) $60 \mathrm{~min}$

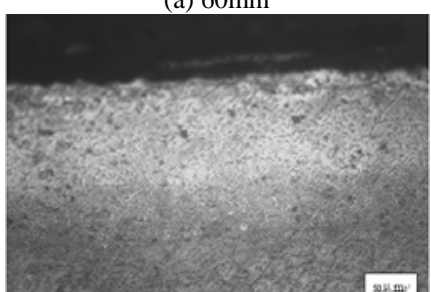

(b) $120 \mathrm{~min}$



(c) $180 \mathrm{~min}$

Fig.4 The decarburized layer of crankshaft for different holding time at $830^{\circ} \mathrm{C}$

The decarburized layer was about $0.05 \mathrm{~mm}, 0.12 \mathrm{~mm}$ and $0.16 \mathrm{~mm}$ with holding $60 \mathrm{~min}, 120 \mathrm{~min}$ and $180 \mathrm{~min}$. The errors were respectively $0.005 \mathrm{~mm}, 0.018 \mathrm{~mm}$ and $0.010 \mathrm{~mm}$ compare to the simulation. The mechanical properties of the material was decreased after the decarburization, can not satisfy the requirement, hardness and wear resistance have 
been seriously affected.

\section{THE ERROR ANALYSIS}

The thickness of decarburization layer is a little error between simulation and experiment. The results were shown in Fig.10.

In the actual process of heat treatment, $40 \mathrm{Cr}$ steel samples were heated to $830^{\circ} \mathrm{C}$ and kept in this temperature with $60 \mathrm{~min}, 120 \mathrm{~min}$ and $180 \mathrm{~min}$. the thickness of decarburization layer and the corresponding depth are $0.05 \mathrm{~mm}, 0.12 \mathrm{~mm}, 0.16 \mathrm{~mm}$, the simulated results were $0.055 \mathrm{~mm}, 0.138 \mathrm{~mm}, 0.170 \mathrm{~mm}$. The temperature of heating furnace and air flow were existed during the experiment. So the results of actual depth of decarburized layer were smaller than the simulated results.

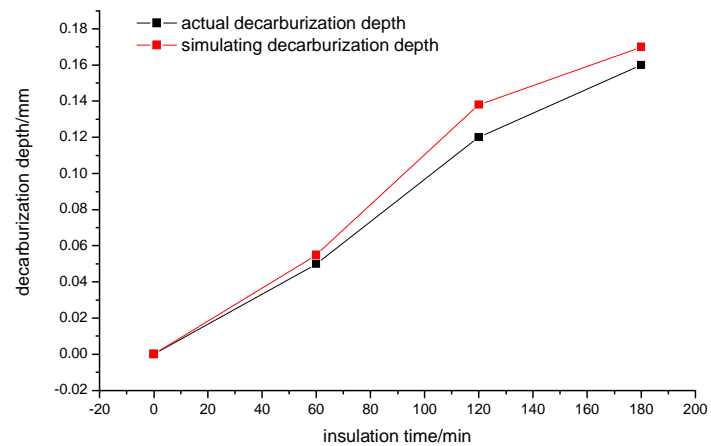

Fig.5 The graph of the depth of decarburization layer about the actual and the simulated

\section{CONCLUSION}

Decarburization of the crankshaft was simulated at $800^{\circ} \mathrm{C}, 830^{\circ} \mathrm{C}, 860^{\circ} \mathrm{C}$ by DEFORM-3D and the experiments were practiced with heat treatment. The results indicated that quenching temperature at $830^{\circ} \mathrm{C}$ was the appropriate.

The depth of decarburization layer on the surface of crankshaft was increased with longer time and higher temperature.

The results of simulation and heat treatment experiments of the depth of decarburization layer are same basically, and the error was from $0.010 \mathrm{~mm}$ to $0.017 \mathrm{~mm}$. The experimental results show that DEFORM-3D software simulation is important for $40 \mathrm{Cr}$ steel to simulate the process of decarburization before the experiment.

\section{REFERENCES}

[1] H.Q.Wen, S.H.Xiang, Y.J.Zhang, et,al. Effect of Heating Temperature on Surface Decarburization of Spring Steel 60Si2Mn[J]. Baosteel Technology, 2008,A(3): 44 -47 (in Chinese )

[2] C.Huang, N.Q.Hang, X.J.Zhang, D.Liu, et,al. Finite Element Simulation on Decarburization of Concasting Billet of High Carbon Steel during Reheating[J]. Special Steel, 2005,A(26):19-26 (in Chinese )

[3] F. Lefevre-Schlick, O. Bouaziz, Y. Brechet, J.D. Embury Compositionally graded steels: The effect of partial decarburization on The mechanical properties of spherodite and pearlite[J]. Materials Science and Engineering, 2008, A(491):80-87

[4] X.Z.Qin., Q.Li. Influence on the Performance of the Decarburization Products[J]. Heat Treatment, 2003, 6 (21):52-56 (in Chinese )

[5] C.M.Li, X.L.Wang, H.J.Yan, et,al: Deform5.30 Metal Forming Finite Element Analysis Example Guide Tutorial[M]. Mechanical Industry Press, Beijing, 2006:1 - 62 (in Chinese )

[6] Z.J. Zhanga, G.Z. Dai, S.N. Wub, L.X. Donga, L.L. Liua. Simulation of 42CrMo steel billet upsetting and its defects analyses during forming process based on the software DEFORM-3D[J]. Materials Science and Engineering, 2009, A (499):49-52

[7] Z.Z. Wang. Fundamentals of Materials Science[M]. Beijing, Mechanical Industry Press, 2004:135-140 (in Chinese )

[8] L.H. Liu, W.Z.Ding. Study on the Decarburization of Spring Steel 60Si2Mn[J]. Heat Trestment, 2005, A(20):6-10 (in Chinese )

[9] X.T.Li., S.L.Zhang, W.J.Wang, et,al. Determination of Decarburized Layer of 4Cr5MoSiV1 Steel in Metallographic Method[J]. Shanxi Metallurgy, 1998, 3(2):39 41 (in Chinese )

[10] P. Egert A. B, A.M. Maliska A, H.R.T. Silva A, C.V. Speller A. Decarburization during plasma nitriding [J]. Surface and Coatings, 1999, 221(5): 33 38 